\title{
Palliative care in non-malignant diseases
}

\author{
D C Traue J R Ross
}

J R Soc Med 2005;98:503-506

Historically, palliative care services have focused on patients with incurable cancer. In its 2004 guidance document Improving Supportive and Palliative Care for Adults with Cancer the National Institute for Clinical Excellence (NICE) emphasizes the importance not only of optimal symptom control but also of psychological, social and spiritual support for patients and their families. ${ }^{1}$ However, the current view is that access to palliative care should be based on need rather than diagnosis, ${ }^{2,3}$ and on that criterion many patients with non-malignant diseases qualify as well. The potential requirement for palliative care in other lifelimiting illnesses is reflected in the National Service Frameworks (NSFs). The NSF for Coronary Heart Disease identifies the need for patients with heart failure to have access to palliative care services for ongoing support and advice; ${ }^{4}$ and the NSF for Renal Services goes further, listing as a quality requirement for patients near the end of life to have 'a jointly agreed palliative care plan, built around their individual needs and preferences' ${ }^{5}$ The NSF for Long-term Conditions, soon to be published, identifies palliative care as one of eleven quality requirements; people with long-term neurological conditions, for example, should have access to a range of palliative care services when near the end of life. ${ }^{6}$

However, despite the general acknowledgment that palliative care services must be extended beyond cancer care, this is not yet common practice. ${ }^{3}$ Part of the reason is a lack of the sort of research that, in advanced cancer, has led to substantial improvement of services. ${ }^{7}$ A consensus statement from the US National Institutes of Health highlights the challenges posed by such conditions as congestive heart failure, end-stage renal disease, chronic obstructive pulmonary disease, liver failure and dementia. ${ }^{8}$ The strongest body of research is on pain management; each condition presents its own special difficulties in end-of-life care.

\section{CHRONIC LUNG DISEASE}

Chronic obstructive pulmonary disease (COPD), which includes chronic bronchitis and emphysema, is the fifth commonest cause of death in England and Wales, accounting for nearly 28000 deaths each year. ${ }^{9}$ It is

Department of Palliative Medicine, Horder Ward, royal Marsden NHS Foundation Trust, Fulham Road, London SW3 6JJ, UK

Correspondence to: Dr J R Ross

E-mail: joy.ross@rmh.nhs.uk predominantly caused by smoking. About 600000 individuals in the UK have had COPD diagnosed and perhaps as many again remain undiagnosed. They are frequent users of primary and secondary care services. ${ }^{9}$

How does COPD compare with lung cancer in terms of 'needs'? In 2001 Edmonds et al. ${ }^{10}$ used post-bereavement interviews with carers to compare experiences. There was no difference in the number of symptoms experienced by the two patient groups either in the last week of life or over the preceding year. However, the groups differed in which symptoms were most troublesome and in their access to either district nurses or palliative care nurses. Patients with lung cancer were more likely to be anorexic ( $76 \%$ versus $67 \%$ ) and those with non-malignant disease were more troubled by shortness of breath (94\% versus $78 \%)$. The patients with cancer had wider access to support systems beyond the general practitioner (district nurses $52 \%$ versus $39 \%$, palliative care services $29 \%$ versus $0 \%$ ).

More recently the same group interviewed carers of 25 patients with COPD to assess symptoms experienced and ease of access to healthcare services. ${ }^{11}$ Although, again, shortness of breath and associated limitation in mobility were the most troublesome symptoms, only 3 out of 25 patients had had access to a specialist respiratory nurse who linked primary and secondary care with a view to maximizing symptom control. This information prompted initiatives to extend palliative care input to COPD patients in the unit concerned. ${ }^{12}$

How do these issues relate to quality of life: Gore et al. ${ }^{13}$ found that patients with COPD scored significantly worse than those with inoperable lung cancer on activities of daily living and physical, emotional and social functioning. They were less likely to have accepted their illness and more likely to be depressed as judged by the Hospital Anxiety and Depression Score (90\% versus 52\%). Once again there was a marked difference in access to services. $30 \%$ of the patients with cancer were in receipt of specialist palliative care support and a further $52 \%$ who had been offered such support were aware they could access it, whereas none of the COPD patients had been offered specialist palliative care services.

There is some debate as to whether a traditional hospice model is suitable for patients with COPD, and concerns have been raised regarding the trajectory of illness in this group. A prospective cohort study in the USA compared patients with lung cancer and COPD to identify differences 
in the course of illness and patterns of care. ${ }^{14}$ Similar proportions in the two groups of patients wanted 'comfort based care' $(>60 \%)$ and did not want ventilation (about $80 \%$ ). However, more COPD patients received ventilation $(70 \%$ versus $20 \%$ ), and a quarter of those ventilated survived to hospital discharge; median two-month and sixmonth survival rates were higher in COPD. Clearly it is no easy task to predict outcomes and meet the expressed wishes of patients about future treatments.

\section{CHRONIC HEART FAILURE}

According to NICE, the incidence of heart failure in the UK is about 1 per 1000 population per year, with survival rates worse than those for either breast or prostate cancer. About 6000 deaths are due to heart failure secondary to coronary heart disease. ${ }^{15}$

Anderson and co-workers ${ }^{16}$ compared the symptoms in end-stage heart failure with those in advanced cancer and found the most troublesome to be shortness of breath and pain, respectively. Both groups of patients reported physical, social and psychological issues to professionals, but social and psychological issues were much more likely to be addressed in the patients with cancer. Various studies have shown pain and shortness of breath to be inadequately addressed in end-stage heart failure, with sub-optimal control even in patients admitted to hospital. ${ }^{17}$ Furthermore, failure to seek (or heed) patients' wishes regarding ongoing management hinders a transition from more organspecific intervention to a palliative symptom-control approach.

A consensus statement on palliative and supportive care in heart failure called for more research in order to extend palliative care to this group, ${ }^{18}$ and among the priorities were evaluation of prognostic indicators, identification of interventions that would improve quality of life, and coordination of care between service providers. Pantilat and Steimle ${ }^{19}$ have offered guidelines for identifying the patients who have most to benefit. A group in Australia have piloted a model that aims to integrate care for patients with heart failure, combining acute and palliative professional input with a multidisciplinary holistic approach. Following skill sharing and training, they found that $50 \%$ of patients were enabled to die at home and that only $8 \%$ required ongoing specialist palliative care input for complex symptom management. ${ }^{20}$

\section{END-STAGE RENAL DISEASE}

Chronic kidney disease affects around 5500 people per million population in the UK. ${ }^{5}$ Despite medical advances, about a quarter of patients with end-stage renal disease (ESRD) die each year. ${ }^{21} 20 \%$ of patients starting dialysis are aged over $75,{ }^{22}$ and the high average age means that co-morbidity is common - diabetes $40 \%$, congestive heart failure/ischaemic heart disease 30\%, cerebrovascular disease $10 \%{ }^{23}$ Thus, as well as dealing with symptoms directly attributable to their renal disease (such as nausea, lethargy, pain, constipation and pruritus), patients are often symptomatic from their concurrent medical conditions resulting in an increased requirement for palliative care. Palliative care must take account of concurrent medical conditions. ${ }^{21,24}$

The NSF for Renal Services specifies that people with established renal failure, having been enabled to live life as fully as possible, should be allowed to die with dignity in a setting of their own choice. This applies to those who decide not to undergo dialysis treatment, those who choose to withdraw from dialysis after a period of treatment, and those who are coming to the end of their lives while continuing dialysis. Currently, however, there is obvious geographic variation within the UK in the level of palliative care provision to patients with end-stage renal disease..$^{25}$ Of the renal units surveyed, only 39\% employed nursing or professions-allied to medicine staff who had palliative care for ESRD as a specified part of their role. Even in units where some staff did have clear responsibility for palliative care, the time allocated to this was negligible. Renal physicians acknowledge the importance of learning how to care for dying patients, but it is an area in which only limited formal education is currently provided. ${ }^{26}$

To meet the comprehensive standards outlined in the NSF, a major review of how palliative care is provided in renal services is required. This issue is being addressed worldwide, and UK units can learn from experience elsewhere. One model being assessed in the USA is the Renal Palliative Care Initiative instituted in New England. ${ }^{21}$ Renal physicians, nurses and social workers were trained in palliative medicine to enable them to provide better end-oflife care, including symptom control, advance care planning and bereavement services.

The symptoms experienced by patients with ESRD overlay considerably with those of patients with cancer; for example, up to half of patients with ESRD are troubled by pain. ${ }^{22}$ However, symptom control techniques are not necessarily transferrable between the two groups. Particular issues arise with altered metabolism of drugs in renal impairment, requiring changes from usual regimens. ${ }^{27}$ As in other non-malignant diseases, there is a lack of evidence to inform practice and more research is required. ${ }^{28}$

\section{BARRIERS TO THE EXPANSION OF PALLIATIVE CARE FOR NON-MALIGNANT DISEASES}

Despite a wide acknowledgment that patients with nonmalignant diseases would benefit from access to palliative care, debate continues as to whether or how this can be 
translated into practice. There are particular concerns about saturation of services because of the longer course of nonmalignant diseases and their less predictable trajectory. Even with cancer, palliative care provision is not uniform across the UK and patients' needs are not always being met. The extension of access to patients with non-malignant diseases might overwhelm the services. However, if organizations clearly define what services they can realistically offer and focus on patients with complex specialist needs rather than specific diagnoses, the prospect becomes less daunting. Even if there is insufficient capacity for specialist palliative care services to support all patients with non-malignant diseases, care could be improved by the dissemination of expertise and knowledge. Healthcare professionals, such as cardiology or respiratory clinical nurse specialists could be trained in the areas of symptom control relevant to their practice, and multiprofessional initiatives, such as breathlessness clinics, could target patients with specific symptoms. Clinical governance encourages evidence-based practice, and the limited research culture of palliative care has been a disadvantage in this respect. Most of the research evidence is from patients with cancer, moreover, specialists in palliative care often know much more about oncology than about nonmalignant diseases. However, with continued collaboration with other specialists and a commitment to ongoing research, this should not in itself be a barrier to extending services.

Another fear is that, because prognostication in nonmalignant disease tends to be less accurate than in cancer, ${ }^{29}$ resources will be saturated by chronically ill patients with heart or lung or liver disease at the expense of those dying with cancer. ${ }^{5}$ However, if the service is truly needs-based, a patient with heart failure and a prognosis of six months may gain more benefit from specialist palliative care input than a patient with lung cancer who has a prognosis of a few weeks; what matters is the severity and complexity of the patient's troubles. As long as clear criteria exist to govern service use, the unpredictable disease trajectory of some non-malignant conditions should not be a barrier to accessing support. ${ }^{30}$

Finally, most of the specialist palliative care services in the UK are provided by the voluntary sector. Some services are predominantly funded by specific cancer-focused charities, such as Macmillan Cancer Relief and Marie Curie Cancer Care. If services are to include non-malignant conditions, a general review of funding will be necessary.

\section{CONCLUSION}

If comprehensive palliative care is to be extended to nonmalignant diseases, existing methods of care provision will need modification. In patients with cancer there has already been a move towards more collaborative interspecialty practice, with palliative care physicians becoming involved at a much earlier stage than formerly. As disease progresses, the balance of input gradually shifts towards palliative strategies, and a purely palliative phase may be identified at the end. In other disciplines this model may need to be adapted to the fluctuating nature of symptoms in nonmalignant diseases. This combined-care approach, with sharing of skills between disciplines, has considerable implications for training, research and funding. Moreover, its introduction must not be allowed to erode service provision for patients with cancer.

The provision of palliative care must be based on need, not diagnosis, and the physical and psychological needs of patients with advanced non-malignant disease differ little from those of patients with cancer. As Doyle has made clear, palliative care is not to be regarded as a luxury, an optional extra. ${ }^{21}$

\section{REFERENCES}

1 NICE. Improving Supportive and Palliative Care for Adults with Cancer. [www.nice.org.uk/page.aspx?o=110005]. Accessed 16 March 2005

2 NHS Executive. A Policy Framework for Commissioning Cancer Services: Palliative Care Services. London: NHS Executive, 1996

3 Addington-Hall J. Reaching Out: Specialist Palliative Care for Adults with Non-malignant Disease. London: National Council for Hospices and Specialist Palliative Care Services, 1995

4 Department of Health. The National Service Framework for Coronary Heart Disease 2000 [www.dh.gov.uk/PublicationsAndStatistics/Publications/ PublicationsPolicyAndGuidance/PublicationsPolicyAndGudance Article/fs/en?CONTENT_ID $=4094275 \& \mathrm{chk}=\mathrm{eTacxC}]$. Accessed 27 February 2005

5 Department of Health. The National Service Framework for Renal Services 2005 [www.dh.gov.uk/PublicationsAndStatistics/Publications /PublicationsPolicyAndGuidance/PublicationsPAmpGBrowsable Document/fs/en?CONTENT_ID=4102941\&chk=aKHxDI]. Accessed 27 February 2005

6 Department of Health. The National Services Framework for Long-term Conditions [www.dh.gov.uk/PublicationsAndStatistics/Publications/ PublicationsPolicyAndGuidance/

PublicationsPolicyAndGuidanceArticle/fs/ en?CONTENT_ID $=4105360 \& \mathrm{chk}=\mathrm{u} 574 \mathrm{kv}]$. Accessed 16 March 2005

7 Riley J, Ross JR. Research into care at the end of life. Lancet 2005

8 National Institutes of Health. NIH State-of-the-Science Conference on Improving End-of-Life Care [http://consensus.nih.gov/ta/024/024End OfLifepostconfINTRO.htm]. Accessed 3 February 2005

9 NICE. Scope for the Development of a Clinical Guideline on the Management of Chronic Destructive Pulmonary Disease. [www.nice.org.uk/ page.aspx?o=213979]. Accessed 16 March 2005

10 Edmonds P, Karlsen S, Khan S, Addington-Hall J. A comparison of the palliative care needs of patients dying from chronic respiratory diseases and lung cancer. Palliat Med 2001;15:287-995

11 Elkington $\mathrm{H}$, White $\mathrm{P}$, Addington-Hall J, Higgs R, Pettinari C. The last year of life of COPD: a qualitative study of symptoms and services

12 Blackler L, Mooney C, Jones C. Palliative care in the management of chronic obstructive pulmonary disease. Br J Nurs 2004;13:518-21

13 Gore JM, Brophy CJ, Greenstone MA. How well do we care for patients with end stage chronic obstructive pulmonary disease 
(COPD)? A comparison of palliative care and quality of life in COPD and lung cancer. Thorax 2000;55:1000-6

14 Claessens MT, Lynn J, Zhong Z, et al. Dying with lung cancer or chronic obstructive pulmonary disease: insights from SUPPORT. Study to understand prognoses and preferences for outcomes and risks of treatments. J Am Geriatr Soc 2000;48(suppl):S146-53

15 NICE. Scope for the Development of a Clinical Guideline on the Management of Heart Failure [www.nice.org.uk/page.aspx?o=213966]. Accessed 16 March 2005

16 Anderson H, Ward C, Eardley A, et al. The concerns of patients under palliative care and a heart failure clinic are not being met. Palliat Med 2001;15:279-86

17 Ward $\mathrm{C}$. The need for palliative care in the management of heart failure. Heart 2002;87:294-8

18 Goodlin SJ, Hauptman PJ, Arnold R, et al. Consensus statement: palliative and supportive care in advanced heart failure. J Card Fail 2004;10:200-9

19 Pantilat SZ, Steimle AE. Palliative care for patients with heart failure. JAMA 2004;291:2476-82

20 Davidson PM, Pauli G, Introna K, et al. Integrated, collaborative palliative care in heart failure: the St George Heart Failure Service experience 1999-2002. J Cardiovasc Nurs 2004;19:68-75

21 Poppel DM, Cohen LM, Germain MJ. The Renal Palliative Care Initiative. J Palliat Med 2003;6:321-26
22 Levy JB, Chambers EJ, Brown EA. Supportive care for the renal patient. Nephrol Dial Transplant 2004;19:1357-60

23 Cohen LM, Germain MJ. Measuring quality of dying in end-stage renal disease. Semin Dial 2004;17:376-9

24 Casey J, Hodson S. Palliative care provision in end-stage renal failure. EDTNA ERCA J 2003;29:4-6

25 Gunda S, Thomas M, Smith S. National survey of palliative care in end-stage renal diseases in the UK. Nephrol Dial Transplant $2005 ; 20: 392-5$

26 Holley JL, Carmody SS, Moss AH, et al. The need for end-of-life care training in nephrology: national survey results of nephrology fellows. Am J Kidney Dis 2003;42:813-20

27 Farrell A, Rich A. Analgesic use in patients with renal failure. Eur J Palliat Care 2000; 7:201-5

28 Johnson A, Bonner A. Palliative care challenges: implications for nurses' practice in renal settings. Contemp Nurse 2004;17:95-101

29 Fox JM. Doubts about a particularly high nephrotoxicity of combination analgesics. Nephrol Dial Transplant 1999;14:2966-8

30 Loftus LA. A collaborative nursing model for advanced non-malignant disease. Int J Palliat Nurs 2000;6:454-48

31 Doyle D. The way forward; policy and practice. In: Promoting Partnership: Planning and Managing Community Palliative Care. London: National Council for Hospices and Specialist Palliative Care Services, 1998 